\title{
Testing a Novel Method for Measuring Sleeping Metabolic Rate in Neonates
}

\author{
Suzanne S Summer MSc RD, Jesse M Pratt MSc MA, Elizabeth A Koch RRT RPFT, \\ and Jeffrey B Anderson MD MPH
}

\begin{abstract}
BACKGROUND: Sleeping metabolic rate (SMR) is used as a proxy for basal metabolic rate in infants, when measurement while awake is not practical. Measuring SMR via indirect calorimetry (IC) can be useful for assessing feeding adequacy especially in compromised neonates. Standard IC equipment, including a hood placed over the head, is not designed for the smallest of patients. Our aim was to determine whether a nonstandard smaller hood measures SMR in neonates similarly compared with a standard large hood. METHODS: SMR was measured in healthy neonates (controls) and those born with single-ventricle congenital heart disease (cases). Two measurements were performed: SMR using a standard large hood and SMR using a smaller hood. Time-to-steady state, minute ventilation $\left(\dot{\mathrm{V}}_{\mathrm{E}}\right)$, and fraction of exhaled carbon dioxide $\left(\mathrm{F}_{\overline{\mathrm{E}} \mathrm{CO}}\right.$; an indicator of data quality) were also measured. Primary outcome was SMR using both hoods. Results are stated as median (interquartile range). Spearman's correlations measured association between the small and large hoods. RESULTS: We studied 9 controls and 7 cases. SMR in controls was not different between the small and large hoods (35.7 [15.14] vs 37.8 [7.41] $\mathrm{kcal} / \mathrm{kg} / \mathrm{d}$, respectively). In cases, SMR with the small hood was significantly greater than that with the large hood $(45.5[4.63] \mathrm{vs} 34.2[8] \mathrm{kcal} / \mathrm{kg} / \mathrm{d}$, $P<.02) . \mathrm{F}_{\overline{\mathrm{E} C O}}$, was significantly higher with the small hood versus the large hood in both groups, and $\dot{V}_{E}$ was significantly lower with the small hood versus the large hood in controls only. The SMRs with the small and large hoods were significantly correlated in the control group $(r=0.80$, $P<.01)$. Time-to-steady state was similar in both groups regardless of hood size. CONCLUSIONS: SMR measured with a small hood yields results similar to those measured with a large hood in healthy neonates without affecting testing time or other aspects of the IC procedure. Furthermore, results in compromised infants suggest that a smaller hood may facilitate SMR testing in this population. Key words: indirect calorimetry; basal metabolic rate; infant; newborn; energy metabolism. [Respir Care 2014;59(7):1095-1100. @ 2014 Daedalus Enterprises]
\end{abstract}

\section{Introduction}

Meeting the nutritional energy needs of newborns and infants is crucial for optimal growth. Healthy infants re-

Ms Summer is affiliated with the Clinical Translational Research Center; Mr Pratt is affiliated with the Division of Biostatistics and Epidemiology; Ms Koch is affiliated with the Division of Pulmonary Medicine; and Dr Anderson is affiliated with the Heart Institute, Cincinnati Children's Hospital Medical Center, Cincinnati, Ohio.

This study was funded by a grant from the Thrasher Research Foundation. Additional support was provided by the National Center for Research Resources and the National Center for Advancing Translational Sciences, National Institutes of Health (Grant 8 UL1 TR000077-04). The authors have disclosed conflicts of interest. quire $\sim 110 \mathrm{kcal} / \mathrm{kg}$ of body weight in the first month of life to promote normal growth and development., ${ }^{1,2}$ Meanwhile, specific energy needs in compromised infants are not defined, yet are higher than those of their healthy

\footnotetext{
Ms Summer presented the results of this study in a poster at the Academy of Nutrition and Dietetics Food and Nutrition Conference and Exposition, held October 6-8, 2012, in Philadelphia, Pennsylvania.

Correspondence: Suzanne S Summer MSc RD, Clinical Translational Research Center, Cincinnati Children's Hospital Medical Center, 3333 Burnet Avenue, Cincinnati, Ohio 45229. E-mail: suzanne.summer@ cchmc.org.
}

DOI: $10.4187 /$ respcare. 02636 
counterparts to fight illness or recover from treatment while still achieving nutritional goals for catch-up growth. ${ }^{3,4}$

While the adequacy of infant feeding can be determined prospectively by regular measurements of length, weight, and head circumference, understanding the energy needs of an individual infant would allow targeted treatment, particularly for those at risk of failure to thrive. Total energy needs for infants are the sum of the basal metabolic rate (BMR), thermic effect of food, and physical activity expenditure, plus energy needed for growth. ${ }^{1}$ The BMR, energy required by the human body at rest, is the largest component of the total energy equation. ${ }^{2}$ BMR is measured via indirect calorimetry (IC), in which a hood placed over the head of the patient collects and measures respiratory gases (inspired oxygen and expired carbon dioxide) to derive metabolic rate. ${ }^{5}$ Standard practice for measuring BMR is to do so while the patient is awake but resting supine. When metabolic rate is measured in infants, sleeping metabolic rate (SMR) has been used as a proxy for BMR because measurement while awake is not typically practical.6,7 Although metabolic rate has been routinely measured via IC in older children and adults, ${ }^{8-11}$ there are limited data in infants and neonates, and devices used to collect respiratory gas exchange can affect results. ${ }^{12}$ Today's commercially available IC equipment, including a hood placed over the head for testing, is not designed to capture respiratory gas exchange in very small, very young infants.

The purpose of this study was to evaluate the use of a smaller hood to measure SMR in neonates and to compare metabolic results using small and large hoods to determine whether use of one hood is preferable over the other when measuring SMR in both healthy and compromised infants.

\section{Methods}

\section{Design}

This was a crossover study using a within-subject design to compare measurement outcomes. This project was part of a larger case-control study investigating energy needs and growth in infants born with complex congenital heart disease (CHD). The study was approved by the Institutional Review Board of Cincinnati Children's Hospital Medical Center.

\section{Subjects}

Cases were infants born with hypoplastic left heart syndrome or another variant of single-ventricle CHD. Patients who met inclusion criteria were recruited during their neonatal hospital admission for cardiac evaluation and surgical palliation. Controls were healthy neonates with no known medical problems. Recruitment of controls was

\section{QUICK LOOK}

\section{Current knowledge}

Indirect calorimetry allows the measurement of caloric requirements to guide nutritional support in at-risk patients. Neonates are a particular challenge for metabolic measurements owing to the lack of specialized equipment and small patient size.

\section{What this paper contributes to our knowledge}

The use of an open circuit dilutional system with a modified hood of reduced size and volume was comparable to that with a standard hood. In compromised infants, the smaller hood facilitated testing.

done via advertisement within our hospital and at local private pediatric practices. Informed consent for cases and controls was obtained from parents or legal guardians. All subjects were enrolled in the study and underwent the procedures described here between May and November of 2011.

\section{Test Preparation}

Infant controls and at least one parent arrived at the Clinical Translational Research Center of Cincinnati Children's Hospital for their scheduled study visit. Upon arrival, the infant was fed his or her normal meal (formula or breast milk) for that time of day. Next, the infant was kept awake and active for as long as possible after feeding, up to $1 \mathrm{~h}$. The 1-h fasting time was used to allow adequate digestion time for the meal consumed plus time for SMR testing while not encroaching upon the next feeding time. Similar preparations were applied to cases, except these infants were already staying in the hospital for treatment of their heart condition, and testing was done in their hospital room. All cases were under cardiorespiratory monitoring throughout the test period, and a cardiology nurse was available if needed.

\section{Measurement of Sleeping Metabolic Rate}

Testing was initiated 1-h post-feeding. SMR was measured via IC using the Vmax Encore indirect calorimeter (CareFusion, San Diego, California). This method uses a ventilated hood placed over the head of the subject to measure oxygen consumption $\left(\dot{\mathrm{V}}_{\mathrm{O}_{2}}\right)$ and carbon dioxide production $\left(\dot{\mathrm{V}}_{\mathrm{CO}_{2}}\right)$, and the Weir equation is used to calculate SMR from these values. ${ }^{13}$ The Vmax system uses a dilution pump to control the speed at which these respiratory gases flow into and out of the hood. In adult testing, 

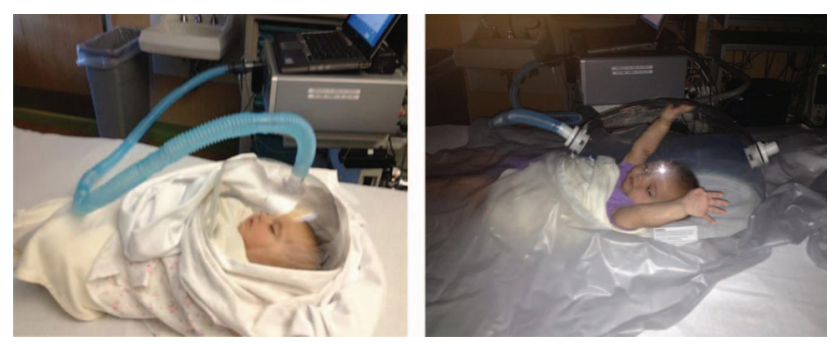

Fig. 1. Infant when being tested under both the small hood (left) and the large hood (right). Photographs published with parental permission.

the standard pump flow is $30 \mathrm{~L} / \mathrm{min}$, and the lowest flow is $15 \mathrm{~L} / \mathrm{min}$. For this study, the system was modified by the inclusion of special software allowing the dilution pump to reach a very low speed $(3 \mathrm{~L} / \mathrm{min})$, which was necessary for capturing the gases in the tiny breaths of infants. Prior to the start of testing, the Vmax flow sensor and gas analyzer were calibrated. The flow sensor was calibrated using a 3-L syringe, providing a known volume of air at various flows. The analyzer was calibrated against two standard gas mixtures: one containing $16 \%$ oxygen $( \pm 0.02 \%)$ and $4 \%$ carbon dioxide $( \pm 0.02 \%)$ and the other containing $26 \%$ oxygen $( \pm 0.02 \%)$. These calibrations are required to ensure accurate measurements of $\dot{\mathrm{V}}_{\mathrm{O}_{2}}$ and $\dot{\mathrm{V}}_{\mathrm{CO}_{2}}$.

IC was performed two times on each subject using either the standard adult (large) hood or a smaller hood (Superdome, Maxtec, Salt Lake City, Utah) typically used for infant oxygen therapy. The volume of the standard hood is $11.25 \mathrm{~L}$, whereas the small hood holds just $4.8 \mathrm{~L}$. The small hood was not equipped with a drape to block out room air, so we fixed blankets and hand towels snugly around the hood to cover openings. Figure 1 shows the same infant under each hood for size and set-up comparison. $\dot{\mathrm{V}}_{\mathrm{O}_{2}}$ and $\dot{\mathrm{V}}_{\mathrm{CO}_{2}}$ were measured for up to $30 \mathrm{~min}$ (or until the infant awoke if before $30 \mathrm{~min}$ ) with each hood. Room environment (lighting, noise, others present) was manipulated to allow the infant to remain asleep as long as possible. Testing with both hoods was usually done backto-back, except in one case, where the infant did not remain asleep after the first test. In this instance, the two hoods were tested on the infant within the same day following the fasting guidelines described previously each time.

The final SMR for each test was determined from an average of values collected while the infant was in steady state, defined as a minimum of $5 \mathrm{~min}$ during which the average $\dot{\mathrm{V}}_{\mathrm{O}_{2}}$ and $\dot{\mathrm{V}}_{\mathrm{CO}_{2}}$ both change by $<10 \%$, and the respiratory quotient changes by $<5 \% .{ }^{14}$ Data from the first $5 \mathrm{~min}$ of each test were excluded, as the metabolic rate during this initial phase has been shown to be higher than the rate measured during subsequent minutes. ${ }^{15}$

In addition to SMR, we recorded average steady-state values of the fraction of exhaled carbon dioxide $\left(\mathrm{F}_{\overline{\mathrm{ECO}}}\right)$.
$\mathrm{F}_{\overline{\mathrm{E}} \mathrm{CO}_{2}}$ is an indicator of the quality of the data collected during testing and helps determine the speed of the dilution pump. During testing, $\mathrm{F}_{\overline{\mathrm{E}} \mathrm{CO}_{2}}$ should be maintained between 0.5 and $1.0 \%$ (ideally, within the optimal range of $0.7-0.8 \%$ ); this range allows the proper calculation of the equations for $\dot{\mathrm{V}}_{\mathrm{O}_{2}}$ and $\dot{\mathrm{V}}_{\mathrm{CO}_{2}}$ that are used to determine $\mathrm{SMR}$. If $\mathrm{F}_{\overline{\mathrm{ECO}}}$ is low, this could indicate that the breath sample is too diluted under the hood, possibly due to shallow breathing in the infant or the dilution pump flow being too high. If $\mathrm{F}_{\overline{\mathrm{ECO}}}$ is high, this could mean that either the breath sample is not diluted enough or the pump flow is too low and may stimulate increased respirations in the infant. We also measured minute ventilation $\left(\dot{\mathrm{V}}_{\mathrm{E}}\right)$, the volume of gas exhaled per minute, as an indicator of breathing frequency. Finally, time-to-reach steady state was recorded to determine if there is a difference between hoods in this respect.

\section{Data Methods}

Data were assessed for normality, and since this assumption was violated, medians and interquartile ranges were computed for time-to-steady state (min), SMR (kcal/ $\mathrm{kg} / \mathrm{d}), \mathrm{F}_{\overline{\mathrm{E}} \mathrm{CO}_{2}}(\%)$, and $\dot{\mathrm{V}}_{\mathrm{E}}(\mathrm{L} / \mathrm{min})$. For both cases and controls, the Wilcoxon signed rank test was used to test for a difference between the small and large hoods. Spearman's correlations were used to measure the association between the SMRs of the small and large hoods in both cases and controls. A $P$ of $<.05$ indicated a statistically significant result. All analyses were performed using SAS 9.3 (SAS Institute, Cary, North Carolina).

\section{Results}

\section{Subjects}

Data from the first 20 subjects in the larger cohort study were analyzed. The SMR measurement was successfully obtained using both hoods on 16 subjects ( 9 controls, 7 cases), and their data were used for our final analysis. Four subjects ( 3 controls, 1 case) were excluded due to time constraints of the family ( 2 controls), subject waking up during testing in at least one of the hoods ( 1 control), and subject going on supplemental oxygen between hoods (1 case).

\section{Sleeping Metabolic Rate, $\mathbf{F}_{\overline{\mathrm{E}} \mathrm{CO}_{2}}$, and $\dot{\mathrm{V}}_{\mathrm{E}}$}

Data are presented as median (interquartile range). In healthy controls, SMR was not significantly different between the measurement with the small hood and the large hood (35.7 [15.14] vs 37.8 [7.41] kcal/kg/d, respectively). However, in cases, SMR using the small hood was significantly greater than SMR measured using the large hood 


\section{Measuring Sleeping Metabolic Rate in Neonates}

Table 1. Controls: Median and Individual Results for Age, Weight, and Metabolic Measures

\begin{tabular}{|c|c|c|c|c|c|c|c|c|}
\hline & \multirow{2}{*}{$\begin{array}{l}\text { Age } \\
\text { (d) }\end{array}$} & \multirow{2}{*}{$\begin{array}{l}\text { Weight } \\
(\mathrm{kg})\end{array}$} & \multicolumn{2}{|c|}{ SMR (kcal/kg) } & \multirow{2}{*}{$P$} & \multicolumn{2}{|c|}{$\mathrm{F}_{\overline{\mathrm{E} C O}}(\%)$} & \multirow{2}{*}{$P$} \\
\hline & & & Small Hood & Large Hood & & Small Hood & Large Hood & \\
\hline Median (IQR) & $26(14)$ & $4.14(0.56)$ & $35.7(15.14)$ & $37.8(7.41)$ & .57 & $0.72(0.10)$ & $0.65(0.15)$ & .01 \\
\hline \multicolumn{9}{|l|}{ Control* } \\
\hline 1 & 22 & 4.1 & 50.24 & 37.80 & & 0.72 & 0.58 & \\
\hline 2 & 29 & 2.8 & 53.93 & 51.43 & & 0.71 & 0.55 & \\
\hline 3 & 24 & 3.98 & 39.20 & 45.98 & & 0.83 & 0.74 & \\
\hline 4 & 25 & 4.54 & 35.68 & 37.22 & & 0.81 & 0.71 & \\
\hline 5 & 30 & 4.14 & 44.44 & 39.13 & & 0.83 & 0.76 & \\
\hline 6 & 18 & 2.95 & 30.51 & 41.36 & & 0.65 & 0.62 & \\
\hline 7 & 35 & 5.23 & 18.93 & 26.77 & & 0.56 & 0.53 & \\
\hline 8 & 26 & 4.3 & 29.30 & 33.95 & & 0.71 & 0.73 & \\
\hline 9 & 30 & 4.7 & 26.81 & 28.30 & & 0.81 & 0.65 & \\
\hline \multicolumn{9}{|c|}{$\begin{array}{l}\text { * Results for individual control subjects (1-9) } \\
\mathrm{SMR}=\text { sleeping metabolic rate } \\
\mathrm{F}_{\overline{\mathrm{E}} \mathrm{CO}}=\text { fraction of exhaled carbon dioxide } \\
\mathrm{IQR}=\text { interquartile range }\end{array}$} \\
\hline
\end{tabular}

Table 2. Cases: Median and Individual Results for Age, Weight, and Metabolic Measures

\begin{tabular}{|c|c|c|c|c|c|c|c|c|}
\hline & \multirow{2}{*}{$\begin{array}{l}\text { Age } \\
\text { (d) }\end{array}$} & \multirow{2}{*}{$\begin{array}{l}\text { Weight } \\
(\mathrm{kg})\end{array}$} & \multicolumn{2}{|c|}{ SMR (kcal/kg) } & \multirow{2}{*}{$P$} & \multicolumn{2}{|c|}{$\mathrm{F}_{\overline{\mathrm{ECO}_{2}}}(\%)$} & \multirow{2}{*}{$P$} \\
\hline & & & Small Hood & Large Hood & & Small Hood & Large Hood & \\
\hline Median (IQR) & $17(14)$ & $3.30(1.1)$ & $45.5(4.63)$ & $34.2(8)$ & .02 & $0.69(0.12)$ & $0.50(0.23)$ & .03 \\
\hline \multicolumn{9}{|l|}{ Case* } \\
\hline 1 & 24 & 3.5 & 50.00 & 47.14 & & 0.70 & 0.63 & \\
\hline 2 & 15 & 4.0 & 45.50 & 29.50 & & 0.79 & 0.57 & \\
\hline 3 & 39 & 4.9 & 45.31 & 36.33 & & 0.68 & 0.70 & \\
\hline 4 & 18 & 3.3 & 48.79 & 34.24 & & 0.77 & 0.47 & \\
\hline 5 & 7 & 2.9 & 48.28 & 30.00 & & 0.65 & 0.39 & \\
\hline 6 & 17 & 2.4 & 44.17 & 37.50 & & 0.53 & 0.40 & \\
\hline 7 & 10 & 3.2 & 39.38 & 27.19 & & 0.69 & 0.50 & \\
\hline
\end{tabular}

(45.5 [4.63] vs 34.2 [8] kcal/kg/d, $P<.02] . \mathrm{F}_{\overline{\mathrm{ECO}}_{2}}$ was significantly higher, although still within the recommended range, with the small hood versus the large hood in both controls and cases. Time-to-steady state was similar in both groups regardless of hood size. Individual and median results for these measures are given in Tables 1 (controls) and 2 (cases). Spearman's rank correlation indicates that the SMRs for the small and large hoods were significantly correlated in the control group $(\mathrm{r}=0.80, P<.01)$; however, there was not enough evidence to conclude that they were correlated in the case group $(\mathrm{r}=0.43, P=.34)$. Finally, $\dot{V}_{\mathrm{E}}$ measured during steady state was significantly lower with the small hood versus the large hood in controls $(3.8[0.1]$ vs $4.5[0.1] \mathrm{L} / \mathrm{min}, P<.01)$. Similar values were found for $\dot{V}_{\mathrm{E}}$ when comparing small and large hoods in cases $(3.7$ [0.1] vs $4.5[0.1] \mathrm{L} / \mathrm{min}$, respectively), but these were not statistically significant.

\section{Discussion}

This is the first study to test the use of a smaller hood to measure SMR in both healthy and compromised neonates. In controls, but not in cases, results for SMR were similar for both hoods. This may be explained by the fact that the controls were slightly older (26 vs $17 \mathrm{~d}$ ) and weighed more (4.1 vs $3.3 \mathrm{~kg}$ ) than the cases, and therefore, because of their size and health status, they were able to produce adequate respiratory gas exchange under either hood. This finding supports our conclusion that the small hood is an acceptable substitute for the standard adult (large) hood 
when performing IC in healthy neonates. Time-to-steady state was also similar in both hoods, and median $\mathrm{F}_{\overline{\mathrm{E} C O}}$ values in cases and controls were within the acceptable range of $0.5-1.0$ for both hoods, providing further evidence that viable measurements can be obtained with both hoods in a healthy population. Interestingly, $\mathrm{F}_{\overline{\mathrm{E}} \mathrm{CO}_{2}}$ values using the small hood were at or near the optimal range (0.7-0.8) to capture respiratory gas exchange and were significantly greater with the large hood in both groups, indicating better gas mixing and less dilution under the small hood. Meanwhile, $\mathrm{F}_{\overline{\mathrm{E}} \mathrm{CO}_{2}}$ with the large hood was below optimal in both groups, and several cases exhibited $\mathrm{F}_{\overline{\mathrm{ECO}}}$ values below the minimum acceptable value of 0.5 . One explanation for this is that the space inside the hood may be too large, resulting in overdilution of the breath sample; in other words, the large hood may not be capturing sufficient respiratory gas exchange in these compromised infants to provide a useful measurement. Bauer et al ${ }^{12}$ performed IC in infants using three breath-sampling devices: a face mask, head hood, and canopy, each with progressively larger volume around the infant's nose and mouth. They found that more accurate results were obtained with the face mask, in part because of its minimal open space around the head. However, the mask is not practical for measuring SMR because affixing it to the infant may cause discomfort and wake the subject during testing. The higher $\mathrm{F}_{\mathrm{ETCO}}$ with the small hood compared with the large hood could produce stimulated respiration, altering the energy expenditure. However, the $\mathrm{F}_{\mathrm{ETCO}_{2}}$ values were still within the optimal range for data collection, and our $\dot{\mathrm{V}}_{\mathrm{E}}$ results confirm normal respiration. Interestingly, we found a higher $\dot{V}_{E}$ with the large hood, which could indicate a greater respiratory demand (increased ventilation) on the infant or overdilution of the exhaled sample, resulting in more variability in the data obtained with this hood.

Most published studies that have measured energy metabolism in an infant population have done so in the sleep state. ${ }^{6,16}$ Although it is known to lower the metabolic rate, ${ }^{1}$ sleep is necessary in infants to achieve the still rested state required for the measurement. Bines and Truby ${ }^{6}$ compared the metabolism measurement in infants while sleeping (SMR) with the measurement while awake (BMR). They found that the SMR was $75 \%$ of the BMR and that there was a significant correlation between the two, with the SMR consistently lower than the BMR.

The values for SMR measured in this study are similar to or slightly lower than those reported in the literature. The SMR of a normal healthy infant ranges from 43 to $60 \mathrm{kcal} / \mathrm{kg} / \mathrm{d}$, and total energy requirements are 107$113 \mathrm{kcal} / \mathrm{kg} / \mathrm{d}^{1}$; therefore, SMR makes up between 40 and $55 \%$ of total energy needs. The SMR measured in our cases with the small hood is $24 \%$ greater than that measured with the large hood. Based on SMR representing
$40-55 \%$ of total needs, the small hood results indicate that the subject needs $84-115 \mathrm{kcal} / \mathrm{kg} / \mathrm{d}$, and the large hood results indicate that the subject needs $62-85 \mathrm{kcal} / \mathrm{kg} / \mathrm{d}$. If we apply these results to a typical infant weighing $4 \mathrm{~kg}$, the difference could be as much as $120 \mathrm{kcal} / \mathrm{d}$, a clinically important amount for a growing child. Thus, there is the risk that an infant would be underfed if following the large hood results, affecting potential for growth and increasing the risk of failure to thrive.

The ability to measure SMR in infants at risk for growth failure could help target nutritional interventions. Infants with complex CHD are one population where this methodology may be very helpful. The measured SMRs in our cases with the small hood are higher than those in the healthy controls. It is hypothesized that infants with complex CHD have higher than normal resting metabolic rates, and this question is being addressed by the larger study in which these cases were also enrolled. Adequate growth and nutrition are critically important in these compromised infants. Poor growth and nutrition are common in infants with CHD, and malnutrition in this population has been estimated to be as high as $53 \% .{ }^{17}$ Poor nutrition in children with complex CHD has been shown to be associated with infection risk, increased hospital stay, and mortality after cardiac surgery. ${ }^{18-20}$ The methods described here may support nutritional interventions in other chronic conditions known or suspected to increase the risk for growth failure in infancy, such as cystic fibrosis, ${ }^{21}$ immune disorders, ${ }^{22}$ and inflammatory bowel disease. ${ }^{23}$ Similarly, babies born prematurely have increased nutritional needs that vary based on gestational age and birth weight. ${ }^{24}$ They also could benefit from this method, which allows SMR to be determined in smaller infants.

This was a pilot study that was part of a larger cohort study. To fully understand the use of this new method and to determine its generalizability to different populations, a larger cohort of subjects with a diverse group of medical conditions should be studied.

\section{Conclusions}

The use of a small size-appropriate hood when measuring metabolic rate in neonates yields results similar to those with the standard large hood while not affecting testing time or other aspects of the IC procedure. Furthermore, the outcomes of metabolic parameters such as $\mathrm{F}_{\overline{\mathrm{E}} \mathrm{CO}_{2}}$ in compromised neonates suggest that using a smaller hood may facilitate SMR testing in this population. A method that accurately measures metabolic rate in high-risk infants would be extremely useful in predicting energy needs and establishing appropriate caloric intake goals for improved outcomes. 


\section{Measuring Sleeping Metabolic Rate in Neonates}

\section{ACKNOWLEDGMENTS}

From the Cincinnati Children's Hospital Medical Center, we thank Adam Rothstein for recruitment and study coordination, Megan Horsley RD and Melissa James RD for clinical nutritional guidance on cases, and Jennifer Hunt RD for conducting SMR measurements.

\section{REFERENCES}

1. Butte NF. Energy requirements of infants. Public Health Nutr 2005; 8(7A):953-967.

2. Heird WC. Modern nutrition in health and disease, 9th edition. In: Shils ME, Olson JA, Shike M, Ross AC, editors. Baltimore: Williams \& Wilkins; 1999:839.

3. Forchielli ML, McColl R, Walker WA, Lo C. Children with congenital heart disease: a nutrition challenge. Nutr Rev 1994;52(10): 348-353.

4. Davis D, Davis S, Cotman K, Worley S, Londrico D, Kenny D, Harrison AM. Feeding difficulties and growth delay in children with hypoplastic left heart syndrome versus d-transposition of the great arteries. Pediatr Cardiol 2008;29(2):328-333.

5. Ferrannini E. The theoretical bases of indirect calorimetry: a review. Metabolism 1988;37(3):287-301.

6. Bines JE, Truby HD. Measurement of resting energy expenditure in infants. J Paediatr Child Health 2004;40(7):380-383.

7. Davies PS. Energy requirements and energy expenditure in infancy. Eur J Clin Nutr 1992;46(Suppl 4):S29-S35.

8. Hosking J, Metcalf BS, Jeffery AN, Voss LD, Wilkin TJ. Little impact of resting energy expenditure on childhood weight and body composition: a longitudinal study (EarlyBird 47). Nutr Res 2011; 31(1):9-13.

9. Brehm BJ, Spang SE, Lattin BL, Seeley RJ, Daniels SR, D'Alessio DA. The role of energy expenditure in the differential weight loss in obese women on low-fat and low-carbohydrate diets. J Clin Endocrinol Metab 2005;90(3):1475-1482.

10. Compher C, Frankenfield D, Keim N, Roth-Yousey L. Best practice methods to apply to measurement of resting metabolic rate in adults: a systematic review. J Am Diet Assoc 2006;106(6):881-903.

11. Mellecker RR, McManus AM. Measurement of resting energy expenditure in healthy children. JPEN J Parenter Enteral Nutr 2009; 33(6):640-645.

12. Bauer K, Pasel K, Uhrig C, Sperling P, Versmold H. Comparison of face mask, head hood, and canopy for breath sampling in flowthrough indirect calorimetry to measure oxygen consumption and carbon dioxide production of preterm infants $<1500$ grams. Pediatr Res 1997;41(1):139-144.

13. Weir JB. New methods for calculating metabolic rate with special reference to protein metabolism. J Physiol 1949;109(1-2):1-9.

14. Haugen HA, Melanson EL, Tran ZV, Kearney JT, Hill JO. Variability of measured resting metabolic rate. Am J Clin Nutr 2003;78(6): 1141-1145.

15. Horner NK, Lampe JW, Patterson RE, Neuhouser ML, Beresford SA, Prentice RL. Indirect calorimetry protocol development for measuring resting metabolic rate as a component of total energy expenditure in free-living postmenopausal women. J Nutr 2001;131(8): 2215-2218.

16. Bauer J, Werner C, Gerss J. Metabolic rate analysis of healthy preterm and full-term infants during the first weeks of life. Am J Clin Nutr 2009;90(6):1517-1524.

17. Cameron JW, Rosenthal A, Olson AD. Malnutrition in hospitalized children with congenital heart disease. Arch Pediatr Adolesc Med 1995;149(10):1098-1102.

18. Leite HP, Fisberg M, de Carvalho WB, de Camargo Carvalho AC. Serum albumin and clinical outcome in pediatric cardiac surgery. Nutrition 2005;21(5):553-558.

19. Sano S, Huang SC, Kasahara S, Yoshizumi K, Kotani Y, Ishino K. Risk factors for mortality after the Norwood procedure using right ventricle to pulmonary artery shunt. Ann Thorac Surg 2009;87(1): 178-185; discussion 185-186.

20. Anderson JB, Beekman RH 3rd, Border WL, Kalkwarf HJ, Khoury PR, Uzark K, et al. Lower weight-for-age z score adversely affects hospital length of stay after the bidirectional Glenn procedure in 100 infants with a single ventricle. J Thorac Cardiovasc Surg 2009;138(2): 397-404.e1.

21. Scaparrotta A, Di Pillo S, Attanasi M, Consilvio NP, Cingolani A, Rapino D, et al. Growth failure in children with cystic fibrosis. J Pediatr Endocrinol Metab 2012;25(5-6):393-405.

22. Barron MA, Makhija M, Hagen LE, Pencharz P, Grunebaum E, Roifman CM. Increased resting energy expenditure is associated with failure to thrive in infants with severe combined immunodeficiency. J Pediatr 2011;159(4):628-632.e1.

23. Abraham BP, Mehta S, El-Serag HB. Natural history of pediatriconset inflammatory bowel disease: a systematic review. J Clin Gastroenterol 2012;46(7):581-589.

24. Cooke RJ, Embleton ND. Feeding issues in preterm infants. Arch Dis Child Fetal Neonatal Ed 2000;83(3):F215-F218. 